\title{
Comparative Study of Fracture Outcome by Dynamic Compression Plating and Locking Compression Plating in Distal Tibial Fracture
}

\author{
Biswakesh Panigrahy ${ }^{1}$ Sanjib kumar Behera ${ }^{2}$ Soubhagya Kumar Hota ${ }^{1}$ Ashok Kumar Nayak ${ }^{1}$ \\ Monalisa Mohapatro 3
}

${ }^{1}$ Department of Orthopaedics, MKCG Medical College and Hospital,

Address for correspondence Biswakesh Panigrahy, MS, Plot no.9, Berhampur, Odisha, India

2 Department of Orthopedics and Joint Replacement Surgery, Lingaraj Nagar, Behind New Bus Stand, Berhampur, Odisha 760001 Care Hospital, Hyderabad, Telangana, India India (e-mail: biswakesh07@gmail.com).

${ }^{3}$ Department of Biochemistry, SCB Medical College and Hospital, Cuttack, Odisha, India

Int J Recent Surg Med Sci 2022;8:95-102.

\begin{abstract}
Keywords

- distal tibia

- dynamic compression plating

- locking compression plating

- AOFAS

- FFI

Introduction Distal tibia fracture with or without fracture of fibula is very commonly encountered in young adults. The treatment protocol is mainly surgical with open reduction and internal fixation (ORIF) with plate and screw-contoured dynamic compression plating (DCP) or precontoured locking compression plating (LCP). In spite of advanced surgery, the outcome is not satisfactory with complications arising in 20 to $50 \%$ of patients. The purpose of this study was to determine the outcome and compare the two different modalities.

Materials and Methods The study includes 30 patients having distal tibial metaphyseal fracture without articular involvement treated with ORIF with plate and screw, contoured intraoperatively DCP and precontoured LCP in the Department of Orthopaedics. Patients were followed up for 12 to 24 months. Results were analyzed clinically (pain, alignment, range of motion, and complication) and radiologically. The patients were assessed according to time of full weight bearing, time of union of fracture, American Orthopaedic Foot and Ankle Society (AOFAS) score, and Foot Functionality Index score.

Results The time of full weight bearing and time of union were found to be statistically significant in DCP and LCP. According to the grading of AOFAS score, in DCP, excellent: 3 cases (20\%), good: 6 cases (40\%), and fair: 6 cases $(40 \%)$. In LCP, excellent 3 cases (20\%), good 8 cases (53.33\%), fair 4 cases (26.66\%) were observed. Conclusion LCP offers stability with early weight bearing and quicker fracture healing. But both groups had the same score at the final follow-up.
\end{abstract}

DOI https://doi.org/ 10.1055/s-0041-1742141. ISSN $2455-7420$.

\footnotetext{
(c) 2022. Medical and Surgical Update Society. All rights reserved. This is an open access article published by Thieme under the terms of the Creative Commons Attribution-NonDerivative-NonCommercial-License, permitting copying and reproduction so long as the original work is given appropriate credit. Contents may not be used for commercial purposes, or adapted, remixed, transformed or built upon. (https://creativecommons.org/ licenses/by-nc-nd/4.0/)

Thieme Medical and Scientific Publishers Pvt. Ltd., A-12, 2nd Floor, Sector 2, Noida-201301 UP, India
} 


\section{Introduction}

Tibial fractures are the most commonly encountered long bone fractures mainly due to high-energy trauma in road traffic accidents or sporting injuries. In today's modernized era, the number of vehicles along with the speed and power of vehicles has increased which has led to increased incidence of trauma to the extent that it is becoming a menace in the society. Distal tibial fractures comprise approximately 10 to $13 \%$ of the tibial fractures ${ }^{1}$ and are approximately 2.9 times more likely in males in the age group of 15 to 49 years. ${ }^{2}$ Distal tibial fractures form a unique category of fracture because of the characteristic tibial anatomical contour and distinctive blood supply pattern. The distal part of diaphysis is flared medially with a $20-\mathrm{cm}$ radius of curvature and twisted $25^{\circ}$. Hence the plate to be used has to be contoured keeping in mind the fitting of this distal medial flare. The characteristic blood supply pattern is such that the blood supply of distal fragment is mainly through lateral and medial branches of anterior tibial artery which anastomose with posterior tibial artery supplying posterior and medial aspects. This is clinically important because after fracture the intramedullary (IM) blood supply is disrupted and the fracture union mainly depends on extramedullary blood supply. ${ }^{3}$

The primary treatment protocol is surgical which offers several advantages like restoring and maintaining length and alignment, early weight bearing, and increased mobility leading to easier and quicker progress to routine daily life activities. Coming to management aspect, the surgical options available are IM nailing and open reduction and internal fixation (ORIF) with plate and screw-contoured dynamic compression plating (DCP) or precontoured locking compression plating (LCP). IM nailing is generally not preferred due to the unique anatomical characteristic of distal tibia which has a wide IM canal in the metaphyseal area. This reduces the stability of the distal part due to the larger diameter of the fragment in proportion to the diameter of the nail. Moreover, it is difficult to reduce and control the metaphyseal fragment because of missing interface between the tibial cortex and the nail, which may be further compounded by additional fracture sites involving the tibial plafond, with intra-articular components. Thus there are higher rates of malunion as compared with plating, which has led to speculations and controversies regarding the treatment of fracture of the distal third of the tibia with IM nailing devices. ${ }^{4-6}$

Distal tibial fractures when planned for plating can be done either by DCP or LCP. In DCP, a 4.5 narrow plate is preferred as it is easily available, can be bent easily by a plate bender, and applied over the reduced fracture, and because of the subcutaneous nature of the distal tibia. The DCP provides a nice construct among the plate, bone, and screw. Furthermore, the plate hole permits different angles of inclination and purchase in bone which helps in achieving axial compression. ${ }^{7-9}$ LCP acts as an internal fixator. The combihole (combination hole) of locking screw with conventional screw gives advantage of both DCP and locking head principle. This plate-screw construct provide a stronger fixation compared with DCP biomechanically. Hence, it helps in accelerated fracture union and reducing the problems of delayed union. LCP is preferred as it is available in a precontoured anatomic manner. However, LCP has disadvantages like it is technically demanding in removing the hardware and higher cost factor. ${ }^{10}$

In spite of advanced surgery, the outcome is not satisfactory with complications like delayed union, malunion, nonunion, wound infection, etc. arising in 20 to $50 \%$ of patients. ${ }^{11-13}$ Hence, the ideal treatment protocol of distal tibial fracture remains controversial. This study aims to explore and give comparative data between DCP and LCP and to highlight the outcomes in both cases.

\section{Materials and Methods}

The present study was a prospective study conducted between March 2019 and March 2020. A total of 30 patients in the age group of 20 to 60 years with extra-articular distal tibial fracture AO type 43A1, 43A2 attending the Emergency Ward of Department of Orthopaedics MKCG, MCH, Berhampur,Odisha, India were selected for this study.

\section{Inclusion Criteria}

All patients with extra-articular distal tibial fracture in the age group of 20 to 60 years, unilateral fractures, closed fracture (with Tscherne grade 0 and 1 soft tissue injury), with good distal fragment, without articular involvement, AO/OTA Fracture Dislocation Classification 43A1, 43A2, without neurovascular deficit of affected limb, and patient willing to give consent for the procedure were included in the study.

\section{Exclusion Criteria}

Patients with open fractures, fracture with Tscherne grade 2 and 3 (gross soft-tissue involvement), with articular involvement, pathological fractures, neurovascular involvement, spinal involvement, known case of bleeding disorders and sickle cell anemia, and associated fractures of other bones of same limb (except fibula) were excluded from the study.

\section{Treatment Protocol}

Primary treatment of patients included administration of prophylactic antibiotics, analgesics, anti-inflammatory drugs, and intravenous (IV) fluids if needed, and treatment of other injuries was done. Detailed history taking and initial radiographic X-rays were done. Patients were randomly selected for surgery with either DCP or LCP. Informed written consent was taken from all patients.

\section{Surgical Procedure}

After spinal block and supine positioning of the patient, tourniquet was applied and proper drapping was done. The fracture site was exposed after giving skin incision, Lazy $\mathrm{S}$ shaped, in the anteromedial aspect of tibia. The fracture margins were freshened and reduced. 


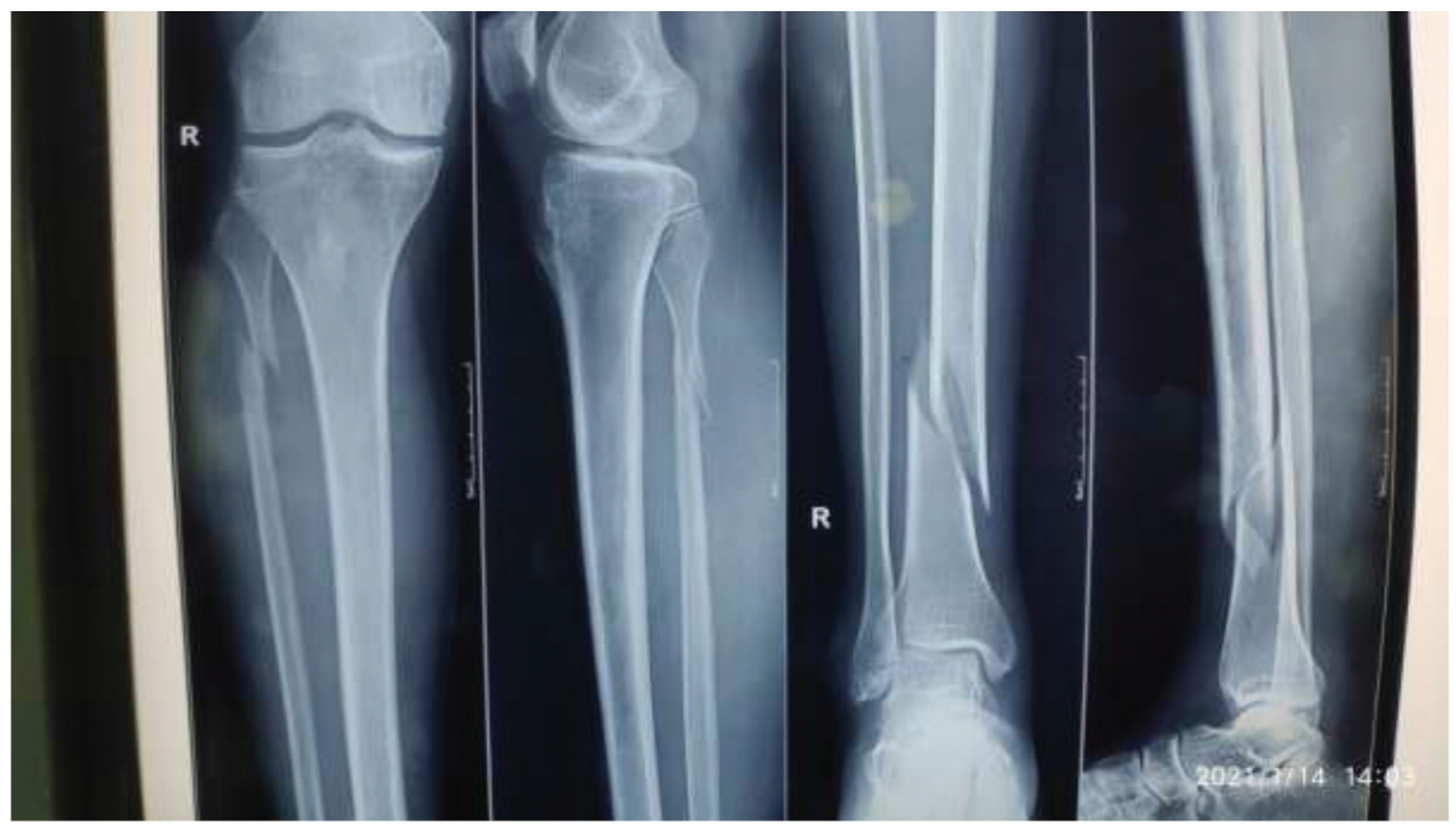

Fig. 1 DCP preoperative X-ray. DCP, dynamic compression plating.

\section{For DCP}

A desired length of plate was chosen keeping in mind to achieve six to eight cortices in the distal fragment (-Fig. 1). Narrow DCP was bent and contoured to sit on distal tibia with a plate bender intraoperatively. After reduction of fracture, it was stabilized with the contoured plate itself or inter-fragmentary screws which were applied and the plate is placed in neutralization mode. The plate is fixed with desired number of screws to achieve six to eight cortices on both sides of fracture. Appropriate lengths of 4.5 cortical screws were preferred. After fixation the wound was closed. Proper care of wound was taken and below knee plaster of Paris (POP) slab was given (- Fig. 2)

\section{For $L C P$}

A desired length of plate was selected roughly three times of the fracture length (- Fig. 3). After reduction, the precontoured anatomical plate was placed on the reduced distal tibia and its position is confirmed under image intensifying TV (IITV). A cortical screw is put to compress the fracture and bring the plate to the bone. Then the distal locking cancellous screws are put and proximal locking cortical screws were put. Using the MIPO (minimally invasive percutaneous osteosynthesis) technique, a vertical incision was made at the level of medial malleolus. A subcutaneous plane was made with a long periosteal elevator. Indirect reduction of fracture was done and LCP is inserted through the incision and fixed with screw. After fixation the wound was closed. Proper care of wound was taken and below knee POP slab was given (-Fig. 4 ).

\section{Fibula Fixation}

In patients presenting with both bone tibia and fibula fracture, fixation of fibula was done basing on the criteria

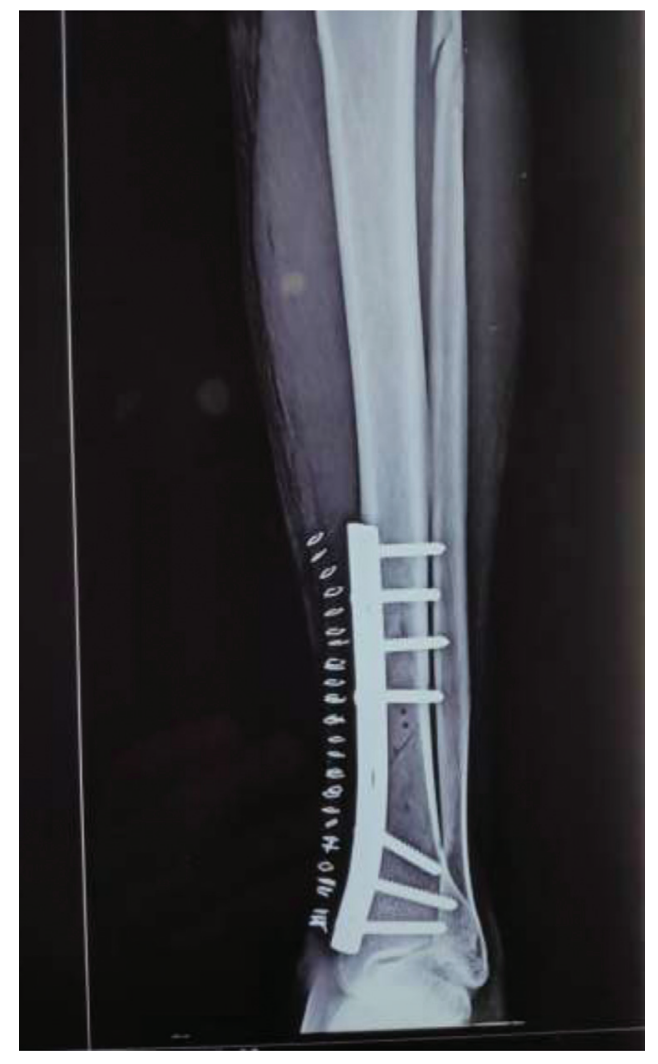

Fig. 2 : DCP postoperative X-ray. DCP, dynamic compression plating.

that fracture was present within $5 \mathrm{~cm}$ of syndesmosis. ${ }^{14}$ Fracture site is opened through lateral longitudinal incision. Without damaging the soft tissue, the fracture site is reached, fracture is reduced and fixed with one-third fibular plate or 


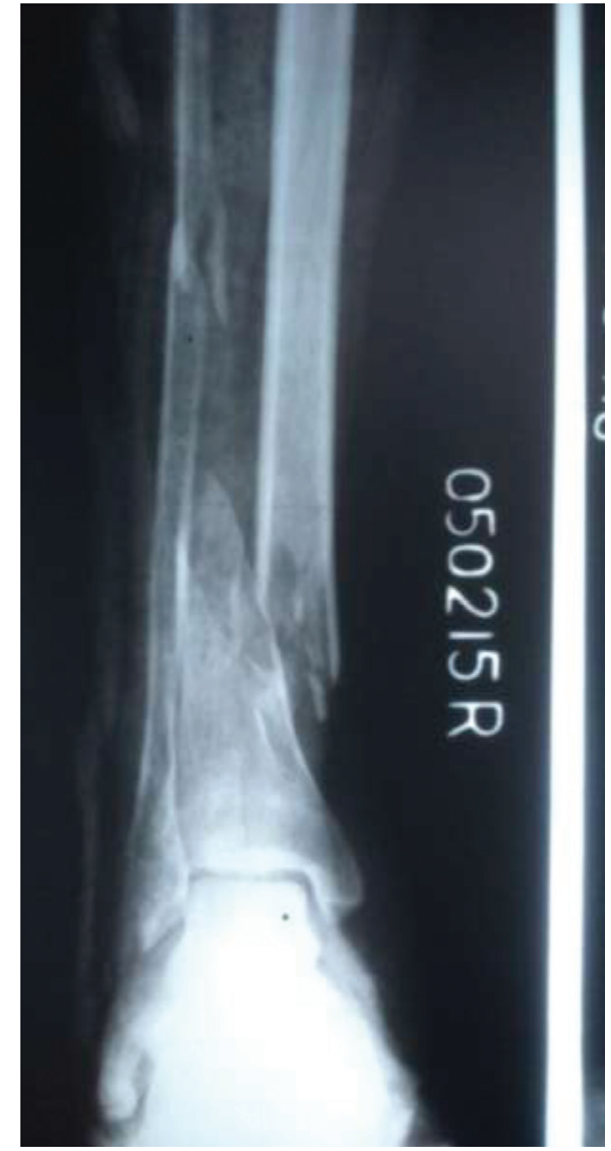

Fig. 3 LCP Pre-op. LCP, locking compression plating.

Recon plate. A gap of four fingers is ensured between two incisions to avoid wound complications.

\section{Postoperative Care}

Patients were assessed clinically and radiologically. Injectable IV antibiotics and analgesics were started. On 3rd or 4th day wound condition was assessed and dressing was done; if wound is healthy, a second dressing is done on 7th or 8th day. On 15th day, stitch removal was done. After the next 15 days, check X-ray was done to see implant position. Wound condition, pain, and infection were assessed and range of motion (ROM) was started. In the second month, ROM was continued and at the end check X-ray was done to see implant status, infection (if any), and callus formation. Toe touching was advised. In the third month, toe touching and ROM were continued. At the end, check X-ray was done to see signs of union, infection status (if any), and localized tenderness. Walking if required was started or delayed by another month. Thereafter individual patient was followed up at every 8-week interval for any complain up to a period of 1 year (-Fig. $\mathbf{5}$ ).

At the final follow-up, ROM was assessed with a goniometer and the American Orthopaedic Foot and Ankle Society (AOFAS) Ankle-Hindfoot Scale score and Foot Functionality Index (FFI) were determined (- Figs. 6-8). The AOFAS scoring system assessed the condition of the patient in three major categories: pain, function, and alignment. According to this

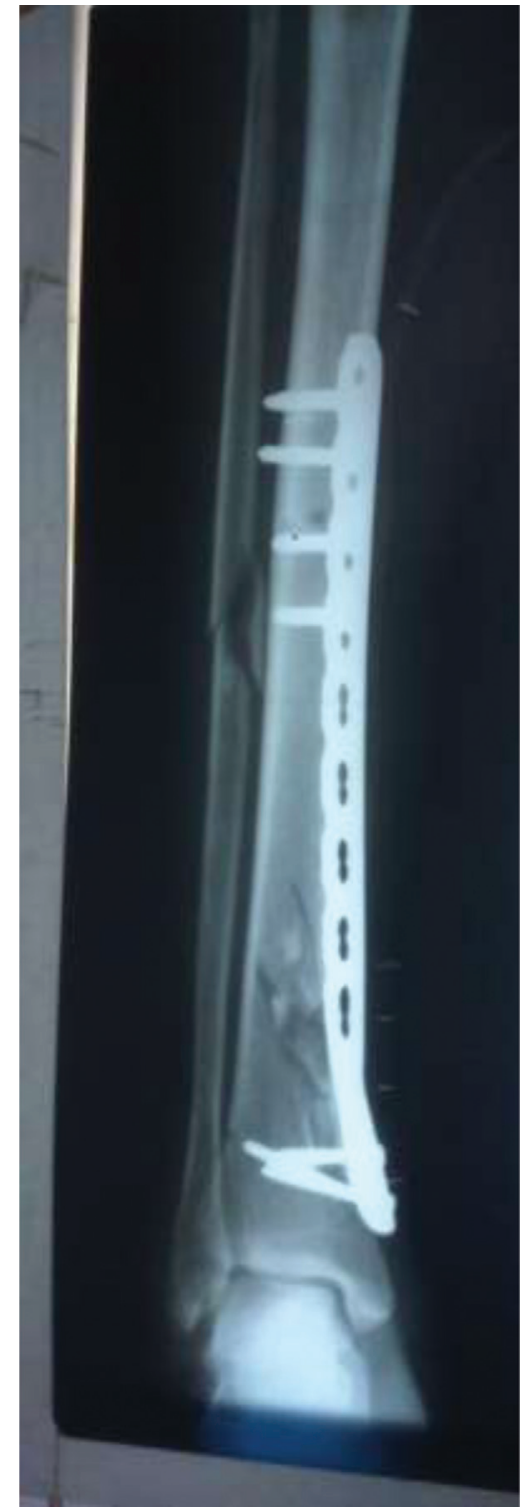

Fig. 4 LCP Post-op. LCP, locking compression plating.

scale, pain is assigned 10 points; function is assigned 50 points which includes activity limitations, support requirements, maximum walking distance in blocks, walking surfaces, gait abnormality, sagittal motion (flexion plus extension), hindfoot motion (inversion plus eversion), ankle-hindfoot stability (anteroposterior, varus-valgus); and alignment is assigned 10 points. Usually, a score between 90 and 100 is excellent, 75 to 89 good, 50 to 74 fair, and $<50$ poor. ${ }^{15}$ The FFI score is devised to know how foot pain has affected patient's ability to manage in daily life. It comprises questions regarding pain and disability on a scale of 1 to 10 over the past week. ${ }^{16}$

\section{Results}

The present study included 30 patients (10 female and 20 male) which were randomly selected for DCP or LCP in equal groups. Depending upon the severity of injury and soft tissue 


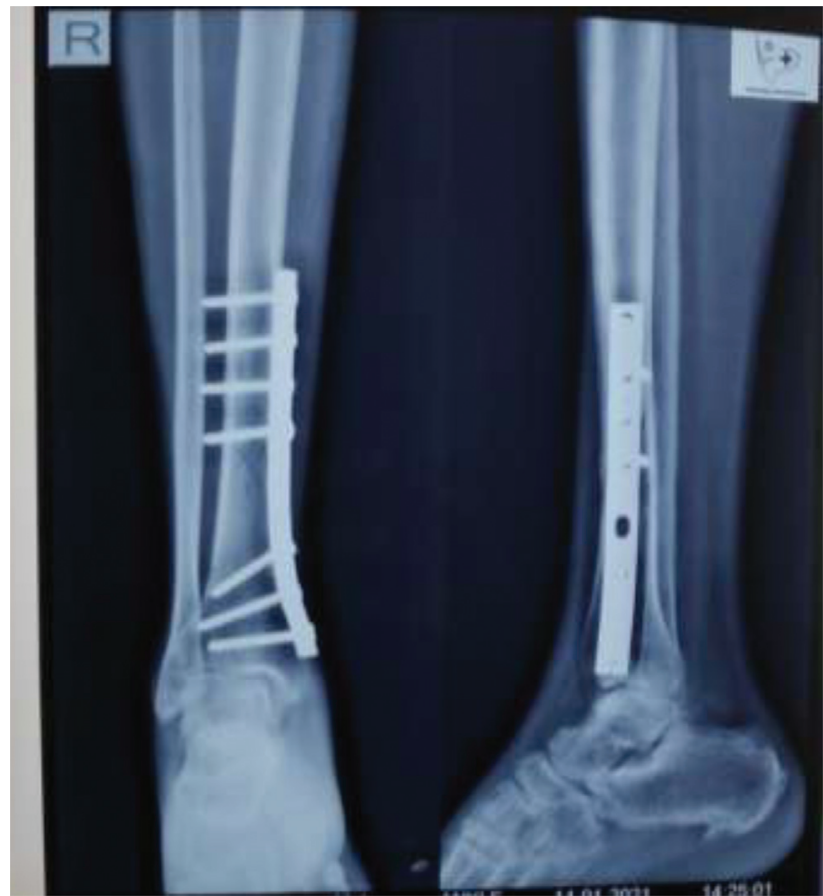

Fig. 5 DCP after 4 months. DCP, dynamic compression plating.

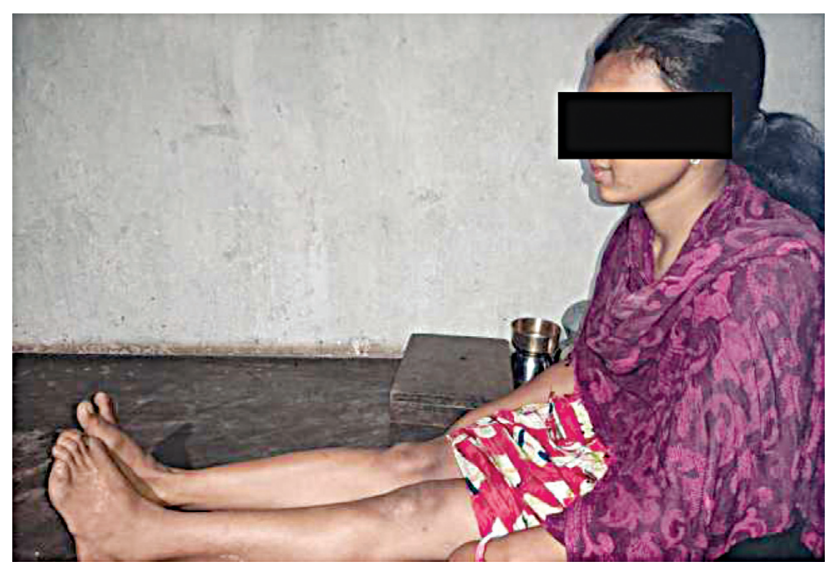

Fig. 6 DCP-ROM. DCP, dynamic compression plating; ROM, range of motion.

status, the decision regarding surgery timing was taken. Hence some cases were operated early, whereas others were delayed. Significant intraoperative complications were not encountered. IITV/C arm was utilized in all LCP cases. The patients were assessed on the basis of time of full weight bearing, time of union of fracture, AOFAS score, and FFI score.

The time of full weight bearing in weeks was found to be up to 12 weeks in 1 case (6.66\%) in DCP as compared with 2 cases (13.33\%) in LCP; 13 to 16 weeks' time in 9 cases (60\%) in DCP and 11 cases (73.33\%) in LCP; 17 to 20 weeks' time in 5 cases (33.33\%) in DCP and 2 cases (13.33\%) in LCP (- Table 1). The union time less than 12 weeks was not present in both groups; 13 to 16 weeks' time in 8 cases $(53.33 \%)$ in DCP and 12 cases ( $80 \%$ ) in LCP; 17 to 20 weeks' time in 7 cases (46.66\%) in DCP and 3 cases (20\%) in LCP (-Table 2 ).

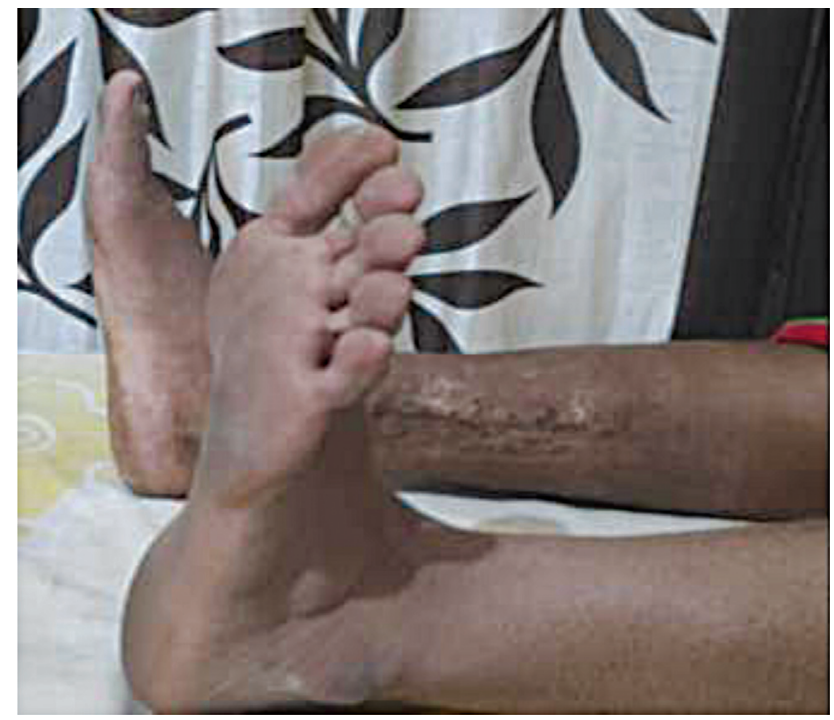

Fig. 7 LCP-ROM. LCP, locking compression plating; ROM, range of motion.

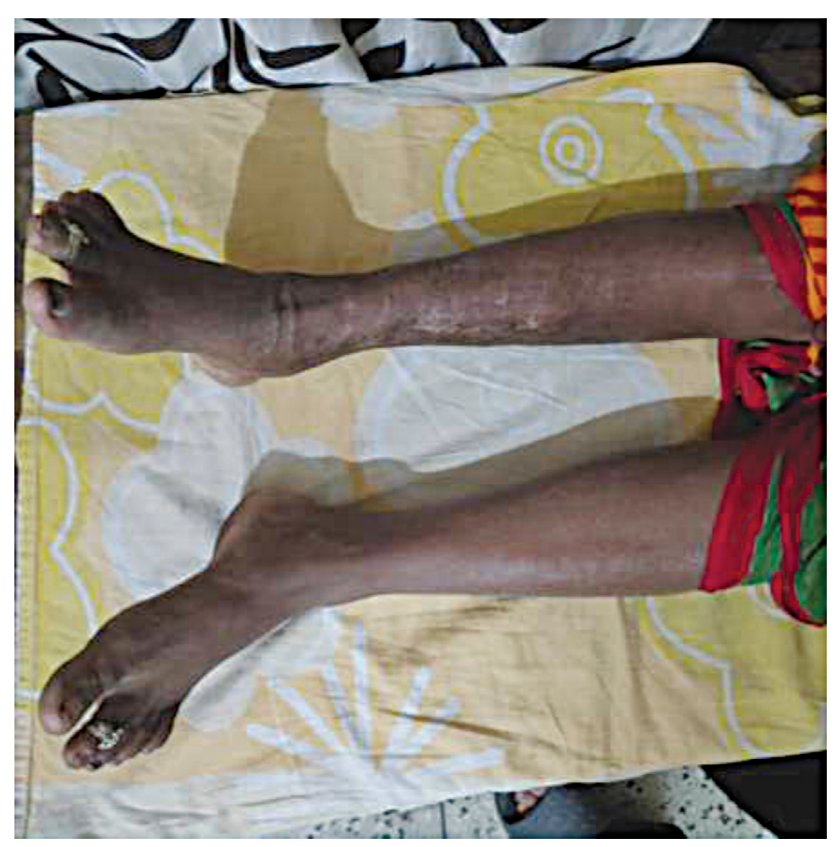

Fig. 8 LCP-ROM. LCP, locking compression plating; ROM, range of motion.

Data are represented as mean \pm standard deviation. Statistical Analysis was done by using SPSS version 20 software. Statistical analysis of data was done using Student's $t$-test. A $p$-value of $<0.05$ was considered significant. Comparing the mean of various parameters, age in years in DCP group was $39.93 \pm 11.164$ and in the LCP group it was $40.47 \pm 9.746$, which was not found to be statistically significant. The time of full weight bearing in weeks was found to be $15.87 \pm 1.807$ in the DCP group whereas in LCP it was $14.47 \pm 1.685$, which was found to be statistically significant $(p=0.037)$. The time of union in weeks was found to be 
Table 1 Comparison of time of full weight bearing in DCP and LCP

\begin{tabular}{|l|l|l|l|l|}
\hline \multirow{2}{*}{ Time in weeks } & \multicolumn{2}{|l|}{ DCP } & \multicolumn{2}{l|}{ LCP } \\
\cline { 2 - 5 } & $\begin{array}{l}\text { No. of } \\
\text { cases }\end{array}$ & $\%$ & $\begin{array}{l}\text { No. of } \\
\text { cases }\end{array}$ & $\%$ \\
\hline $\begin{array}{l}\text { Up to } \\
12 \text { weeks }\end{array}$ & 1 & 6.66 & 2 & 13.33 \\
\hline $13-16$ & 9 & 60 & 11 & 73.33 \\
\hline $17-20$ & 5 & 33.33 & 2 & 13.33 \\
\hline Total & 15 & 100 & 15 & 100 \\
\hline
\end{tabular}

Abbreviations: DCP, dynamic compression plating; LCP, locking compression plating.

Table 2 Comparison of union time in DCP and LCP

\begin{tabular}{|l|l|l|l|l|}
\hline \multirow{2}{*}{ Time in weeks } & \multicolumn{2}{|l|}{ DCP } & \multicolumn{2}{l|}{ LCP } \\
\cline { 2 - 5 } & $\begin{array}{l}\text { No. of } \\
\text { cases }\end{array}$ & $\%$ & $\begin{array}{l}\text { No. of } \\
\text { cases }\end{array}$ & $\%$ \\
\hline$<12$ weeks & - & & - & \\
\hline $13-16$ & 8 & 53.33 & 12 & 80 \\
\hline $17-20$ & 7 & 46.66 & 3 & 20 \\
\hline Total & 15 & 100 & 15 & 100 \\
\hline
\end{tabular}

Abbreviations: DCP, dynamic compression plating; LCP, locking compression plating.

$16.60 \pm 1.549$ in DCP, whereas in LCP it was $15.53 \pm 1.302$, which was statistically significant $(p=0.051)$.

The AOFAS score in DCP was $81.27 \pm 14.033$ and in LCP it was $84.27 \pm 12.360$, which was not statistically significant. The FFI score in DCP was $36.00 \pm 7.260$ and in LCP it was $33.80 \pm 8.291$, which was statistically not significant (-Table 3).

The AOFAS score according to the grading was found to be excellent (90-100) in 3 cases (20\%) in DCP similar to 3 cases (20\%) in LCP. Good (75-89) in 6 cases (40\%) in DCP as compared with 8 cases (53.33\%) in LCP. Fair (50-74) in 6 cases (40\%) in DCP as compared with 4 cases (26.66\%) in LCP, and poor $(<50)$ was not seen in both groups ( - Table 4 ).

Complication like infection occurred in 3 cases (20\%) of DCP, whereas it occurred only in 2 cases (13.33\%) in LCP
Table 4 Comparison of AOFAS score in DCP and LCP

\begin{tabular}{|l|l|l|l|l|}
\hline \multirow{2}{*}{ AOFAS score } & \multicolumn{2}{|l|}{ DCP } & \multicolumn{2}{l|}{ LCP } \\
\cline { 2 - 5 } & $\begin{array}{l}\text { No. of } \\
\text { cases }\end{array}$ & $\%$ & $\begin{array}{l}\text { No. of } \\
\text { cases }\end{array}$ & $\%$ \\
\hline Excellent, 90-100 & 3 & 20 & 3 & 20 \\
\hline Good, 75-89 & 6 & 40 & 8 & 53.33 \\
\hline Fair, 50-74 & 6 & 40 & 4 & 26.66 \\
\hline Poor, $<50$ & - & & - & \\
\hline Total & 15 & 100 & 15 & 100 \\
\hline
\end{tabular}

Abbreviations: AOFAS, American Orthopaedic Foot and Ankle Society; DCP, dynamic compression plating; LCP, locking compression plating.

Table 5 Complications in DCP and LCP

\begin{tabular}{|l|l|l|l|l|}
\hline \multirow{3}{*}{ Infection } & \multicolumn{2}{|l|}{ DCP } & \multicolumn{2}{|l|}{ LCP } \\
\cline { 2 - 5 } & $\begin{array}{l}\text { No. of } \\
\text { cases }\end{array}$ & $\%$ & $\begin{array}{l}\text { No. of } \\
\text { cases }\end{array}$ & $\%$ \\
\cline { 2 - 5 } & 3 & 20 & 2 & 13.33 \\
\hline
\end{tabular}

Abbreviations: DCP, dynamic compression plating; LCP, locking compression plating.

(-Table 5). In cases of infection, patients came for regular follow-up. In one case of DCP and one case of LCP, infection started from day of stitch removal and persisted. Status of infection was assessed by pus culture, differential count, total leucocyte count, erythrocyte sedimentation rate, and Creactive protein, and culture-specific antibiotics were started. Radiologically no sign of implant failure was observed, so the patient was allowed to proceed with implant under observation. With subsequent cultures coming negative, the patient was allowed to continue with regular activities and wait until union of bone. At 12 to 15 months, implants were removed with thorough debridement of tissue. Postimplant surgery was uneventful. Implant failure was not encountered in either of DCP or LCP.

\section{Discussion}

Distal tibial fractures are complex cases which need appropriate treatment to prevent complications. The tibia as a

Table 3 Comparison of the mean of parameters in DCP and LCP

\begin{tabular}{|l|l|l|l|}
\hline Parameter & DCP & LCP & $p$-Value \\
\hline Age in years & $39.93 \pm 11.164$ & $40.47 \pm 9.746$ & 0.890 \\
\hline Full weight bearing in weeks & $15.87 \pm 1.807$ & $14.47 \pm 1.685$ & 0.037, significant \\
\hline Union time in weeks & $16.60 \pm 1.549$ & $15.53 \pm 1.302$ & 0.051 , significant \\
\hline AOFAS score & $81.27 \pm 14.033$ & $84.27 \pm 12.360$ & 0.539 \\
\hline FFI score & $36.00 \pm 7.260$ & $33.80 \pm 8.291$ & 0.446 \\
\hline
\end{tabular}

Abbreviations: AOFAS, American Orthopaedic Foot and Ankle Society; DCP, dynamic compression plating; FFI, Foot Functionality Index; LCP, locking compression plating. 
whole is subcutaneous and distal tibia is relatively less vascular. Since this area has less soft tissue coverage, any injury causing fracture also results in extensive soft tissue damage. The energy causing the fracture determines the degree and severity of soft tissue injury. Hence care of the soft tissue is of paramount importance in dealing with these fractures. Tibial fractures are also commonly associated with fracture of fibula as these are typically caused by twisting force which results in oblique and spiral fracture. ${ }^{17}$ Fixation of fibula is done concomitantly with tibial fixation to restore length of tibia and to control rotation. The goal of the operative treatment is to obtain anatomical alignment of the joint surface by providing enough stability to allow early movement. This can be achieved by using techniques that minimize osseous and soft tissue devascularization which can decrease the complications resulting from treatment. $^{18-20}$

IM nailing is the biological way for avoiding periosteal stripping and maintaining reduction with fracture healing by peripheral callus bridging. ${ }^{21}$ However, a larger diameter of distal medullary canal causes malalignment of nail and has a higher rate of malunion as compared with plating. ${ }^{3}$ The next alternative is ORIF with plates and screws, which provide rigid fixation and also give better anatomical alignment than IM nail. $^{22}$ The innovative concept of LCP has revolutionized the treatment of distal tibial fracture by replacing the previous extreme approach of injuring the periosteum and blood supply with a less traumatizing percutaneous approach and thereby reducing the period of immobilization. ${ }^{23,24}$ However, LCP is technically demanding with the need for $\mathrm{C}$ arm and also has been associated with increased complication rates. ${ }^{25,26}$ Amidst the increased use of locking plates, DCP has not lost its charm. DCP is economical and can be used in less advanced set-ups, for which it is preferred by surgeons. ${ }^{27}$

In our present study, we have observed that the time of weight bearing and union time are achieved earlier in LCP as compared with DCP, which is found to be statistically significant. The AOFAS score was found to be excellent in 20\% cases in both groups and good in $53.33 \%$ in the LCP group as compared with $40 \%$ in the DCP group. However, at the final follow-up, AOFAS and FFI were found to be statistically not significant. The infection rate was found to be $20 \%$ in DCP and $13.33 \%$ in the LCP group, which were treated. Both LCP and DCP patients ultimately united and eventually went back to routine daily life.

\section{Conclusion}

Distal tibial fracture remains a therapeutic challenge for orthopaedic surgeons. Amongst various modalities of treatment, IM nailing was considered previously and now it has been replaced by ORIF with DCP or LCP. LCP offers stability with early weight bearing and quicker fracture healing. DCP being a simple implant achieves the same landmark of weight bearing and union in a slightly more time frame as compared with LCP. However, DCP has the advantage of less use of C-arm/IITV and easy removal of implant. Both groups had the same effect after a long period of follow-up and the type of plate had hardly any effect on patient's lifestyle. Thus it is reduction and alignment, care of soft tissue, and complication management which influence the result of fracture rather than the type of plate used. Hence we advocate the judicious use of DCP and LCP depending upon the patient, surgical skill, experience, and resources available.

\section{Ethical Approval}

This study was approved by the Institutional Ethics Committee at the place of work of the corresponding author.

Conflict of Interest

None declared.

\section{References}

1 Wang B, Zhao Y, Wang Q et al. Minimally invasive percutaneous plate osteosynthesis versus intramedullary nail fixation for distal tibial fractures: a systematic review and meta-analysis. J Orthop Surg Res 2019;14(01):456

2 Singer BR, McLauchlan GJ, Robinson CM, Christie J. Epidemiology of fractures in 15,000 adults: the influence of age and gender. J Bone Joint Surg Br 1998;80(02):243-248

3 Finkemeier CG, Neiman R, Mallon Z. Tibial and fibula shaft fractures. In: Chapman MW, James MA, eds. Chapman's Comprehensive Orthopaedic Surgery. 2019:822-854

4 Tarr RR, Wiss DA. The mechanics and biology of intramedullary fracture fixation. Clin Orthop Relat Res 1986;(212):10-17

5 Ekeland A, Thoresen BO, Alho A, Strömsöe K, Follerås G, Haukebø A Interlocking intramedullary nailing in the treatment of tibial fractures. A report of 45 cases. Clin Orthop Relat Res 1988; (231):205-215

6 Wiss DA. Flexible medullary nailing of acute tibial shaft fractures. Clin Orthop Relat Res 1986;(212):122-132

7 Müller ME. Treatment of nonunions by compression. Clin Orthop Relat Res 1965;43(43):83-92

8 Danis R. The classic. The aims of internal fixation. Clin Orthop Relat Res 1979;(138):23-25

9 Allgöwer M, Ehrsam R, Ganz R, Matter P, Perren SM. Clinical experience with a new compression plate "DCP". Acta Orthop Scand Suppl 1969;125:45-61

10 Azboy I, Demirtaş A, Uçar BY, Bulut M, Alemdar C, Ozkul E. Effectiveness of locking versus dynamic compression plates for diaphyseal forearm fractures. Orthopedics 2013;36(07): e917-e922

11 Marsh JL, Saltzman CL. Ankle fractures. In: Bucholz RW, Heckman JD, Court-Brown CM, eds. Rockwood \& Green's Fractures in Adults. 2006:2147-2247

12 McFerran MA, Smith SW, Boulas HJ, Schwartz HS. Complications encountered in the treatment of pilon fractures. J Orthop Trauma 1992;6(02):195-200

13 Teeny SM, Wiss DA. Open reduction and internal fixation of tibial plafond fractures. Variables contributing to poor results and complications. Clin Orthop Relat Res 1993;(292):108-117

14 Uchiyama E, Suzuki D, Kura H, Yamashita T, Murakami G. How much length of distal fibula is needed for ankle stability? Paper presented at: 51st Annual Meeting of the Orthopaedic Research Society; Washington, D.C., February 20-23, 2005

15 Joveniaux P, Ohl X, Harisboure A, et al. Distal tibia fractures: management and complications of 101 cases. Int Orthop 2010;34 (04):583-588

16 Budiman-Mak E, Conrad KJ, Roach KE. The Foot Function Index: a measure of foot pain and disability. J Clin Epidemiol 1991;44(06): $561-570$ 
17 Leonard M, Magill P, Khayyat G. Minimally-invasive treatment of high velocity intra-articular fractures of the distal tibia. Int Orthop 2009;33(04):1149-1153

18 Collinge CA, Sanders RW. Percutaneous plating in the lower extremity. J Am Acad Orthop Surg 2000;8(04):211-216

19 Collinge C, Sanders R, DiPasquale T. Treatment of complex tibial periarticular fractures using percutaneous techniques. Clin Orthop Relat Res 2000;(375):69-77

20 Helfet DL, Shonnard PY, Levine D, Borrelli J Jr. Minimally invasive plate osteosynthesis of distal fractures of the tibia. Injury 1997;28 (Suppl 1):A42-A47

21 Sahni G, Mann HS, Singh R, Bhalla T. Comparative study of interlock nailing versus dynamic compression plating in fractures of tibia - a study of sixty cases. Indian J Orthop Surg 2015;1(04):197-204

22 Im GI, Tae SK. Distal metaphyseal fractures of tibia: a prospective randomized trial of closed reduction and intramedullary nail versus open reduction and plate and screws fixation. J Trauma 2005;59(05):1219-1223

23 Blatter G, Weber BG. Wave plate osteosynthesis as a salvage procedure. Arch Orthop Trauma Surg 1990;109(06):330-333

24 Farouk O, Krettek C, Miclau T, Schandelmaier P, Guy P, Tscherne H. Minimally invasive plate osteosynthesis and vascularity: preliminary results of a cadaver injection study. Injury 1997;28(Suppl 1):A7-A12

25 Schepers T, Van Lieshout EM, De Vries MR, Van der Elst M. Increased rates of wound complications with locking plates in distal fibular fractures. Injury 2011;42(10):1125-1129

26 Kumar S, Kumar R. Assessment of functional outcome of lower third tibial fracture fixation with distal tibial locking plate: an observational study. Nat J Clin Orthop 2020;4(03):19-21

27 Syed H, Amin M, Talha M, Anwer A. MIPO in distal tibial metaphyseal fractures a comparison among DCP, LCP and pre-contoured DT-LCP. PAFMJ 2019;69(03):554-559 